\title{
DESENVOLVIMENTO DE EMPRESAS RURAIS \\ DO TERRITÓRIO DO SISAL E AS RELAÇOES URBANO-RURAL: UM \\ PROCESSO \\ REVERSO NA PEQUENA CIDADE?
}

\author{
Betânia Lima Machado de Souza ${ }^{1}$; Onildo Araújo da Silva ${ }^{2}$ \\ 1. Bolsista PIBIC/CNPq, Graduanda de bacharelado em Geografia, Universidade Estadual de Feira de Santana, e- \\ mail: betaniauefs@gmail.com \\ 2. Orientador, Departamento de Ciências Humanas e Filosofia, Onildo Araújo Silva, Universidade Estadual de Feira \\ de Santana, e-mail: fssilvafs@hotmail.com
}

PALAVRAS-CHAVE: empresas rurais; desenvolvimento; urbano-rural.

\section{INTRODUÇÃO}

Para Destarte (apud ANCELES 2001), a empresa rural é unidade de produção para uma comunidade mais ampla, onde se associam terra, trabalho, capital e técnica, tudo dirigido organicamente a um fim econômico. O desenvolvimento rural é definido como um processo que resulta de ações articuladas, que visam induzir mudanças socioeconômicas e ambientais no âmbito do espaço rural para a melhoria na renda, na qualidade de vida e do bem-estar das populações. As empresas rurais do Território do Sisal (Figura 1) se configuram pelas diversificações e transformações socioambientais que se deram na região rural do Território do Sisal a partir da década de 1990, principalmente com o eixo da mineração.

Este estudo buscou-se realizar o levantamento quantitativo das empresas rurais dos pequenos municípios do Território do Sisal (BA), a fim de verificar possíveis impactos deste processo na dinâmica das relações urbano rural, identificando essa reorganização do espaço através da implantação das empresas.

Para a realização do estudo elaborou-se um banco de dados com apoio também do SIG (Sistema de Informações Geográficas), com a finalidade de contribuir na investigação de fenômenos espaciais relacionados às empresas rurais e a relação urbano-rural das pequenas cidades do Território do Sisal.

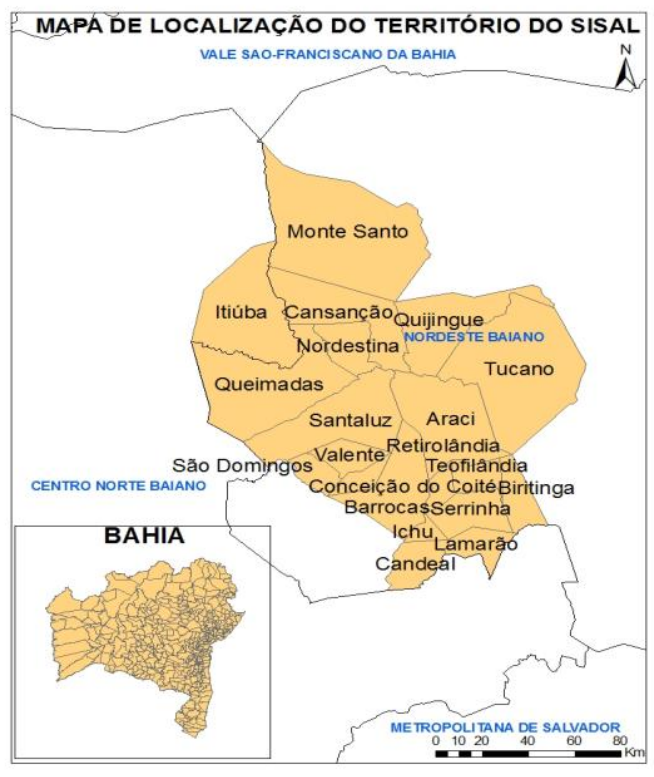

Figura 1: Mapa de Localização do Território do Sisal Elaboração: Betânia Machado, 2017. 


\section{MATERIAL E MÉTODOS OU METODOLOGIA (ou equivalente)}

A metodologia utilizada para alcançar os resultados obtidos, foi fundamentada inicialmente pelo levantamento bibliográfico sobre empresas rurais, o Território do Sisal e a dinâmica nas pequenas cidades. Na etapa posterior, elaborou-se um banco de dados SIG, com o intuito de manipular e analisar as informações socioeconômicas, sobretudo referentes aos limites políticos e administrativos municipais da Bahia (IBGE, 2010), empresas rurais (FIEB, 2010) E o PIB (Produto Interno Bruto) (SEI,2002,2005,2010 e 2014). Em seguida, construiu-se quadro, gráficos e para evidenciar as empresas do Território do Sisal, dando Ênfase ao Território do Sisal. Em decurso, buscou-se analisar os dados para relacioná-los ao processo de relação da dinâmica urbano-rural.

\section{RESULTADOS E/OU DISCUSSÃO (ou Análise e discussão dos resultados)}

Neste estudo, considerou-se a pesquisa das empresas rurais do Território do Sisal, a fim de analisar os possíveis impactos deste processo na dinâmica das relações urbano rural, identificando essa reorganização do espaço através da implantação das empresas. Existem mais empresas urbanas do que rurais nos municípios do Território e as empresas rurais estão ligadas principalmente na produção de artefatos em couro e a extração mineral e metais preciosos.

Percebe-se que das empresas existentes do Território do Sisal, a maioria delas, localiza-se na zona urbana. Das 239 empresas registras no Guia Industrial do Estado da Bahia (FIEB), 213 estão na zona urbana e apenas 26, na zona rural (Gráfico 1).

Observa-se que dos municípios do Território do Sisal, o município de Serrinha e Conceição do Coité, apresentam números de empresas superiores aos demais municípios, tanto na zona urbana, quanto na zona rural, refletindo assim no desenvolvimento socioeconômico e populacional desses municípios que possui destaque, em detrimento dos demais do Território do Sisal.

Os municípios de Araci, Cansanção, Ichu, Retirolândia, Santaluz, São Domingos, Tucano e Valente se destacam entre os municípios, (com exceção de Serrinha e Conceição do Coité) por apresentarem mais de cinco empresas registradas. Os municípios de Candeal e Monte Santo foram os municípios que apresentaram os menores registros de empresas, mostrando pouca expressividade (Gráfico 2).

As produções encontradas nas empresas rurais se baseiam no eixo da mineração, estruturas de concreto, britamento de pedras, calçados, especiarias, cordoaria e sisal, produtos de cerâmica e artefatos em couro. Mas o que se destaca é o eixo da mineração e a produção de metais preciosos, principalmente nos municípios de Santaluz, Nordestina e Barrocas (Quadro 1).

Os municípios de Santaluz, Nordestina e Tucano, apresentam um maior número de empresas rurais registradas (Figura 2), sendo que em Tucano predomina as produções de artefatos em couro, tendo quatro empresas destinadas a produções de bolsas, carteiras, etc. Em Santaluz e Nordestina a base das produções das empresas rurais se baseia na extração de minério e metais preciosos. 


\begin{tabular}{|c|c|c|c|}
\hline \multirow{2}{*}{\multicolumn{2}{|c|}{ TOTAL DE EMPRESAS DO TERRITÓRIO DO SISAL }} & \multirow[b]{2}{*}{$\begin{array}{c}\text { TIPOS DE PRODUÇÕES } \\
\text { DAS EMPRESAS } \\
\text { RURAIS }\end{array}$} & \multirow[b]{2}{*}{$\begin{array}{l}\text { NÚMERO DE } \\
\text { EMPRESAS }\end{array}$} \\
\hline & & & \\
\hline & \multirow{8}{*}{$\begin{array}{l}\text { Quantidade de Empresas } \\
\text { Urbanas } \\
\text { Quantidade de Empresas } \\
\text { Rurais }\end{array}$} & $\begin{array}{l}\text { MINÉRIOS E METAIS } \\
\text { PRECIOSOS }\end{array}$ & 7 \\
\hline & & $\begin{array}{l}\text { ESTRUTURAS DE } \\
\text { CONCRETO } \\
\end{array}$ & 3 \\
\hline & & $\begin{array}{l}\text { BRITAMENTO DE } \\
\text { PEDRAS }\end{array}$ & 2 \\
\hline & & CALÇADOS & 3 \\
\hline & & ESPECIARIAS & 3 \\
\hline & & CORDOARIA E SISAL & 2 \\
\hline & & $\begin{array}{l}\text { PRODUTOS DE } \\
\text { CERÂMICA }\end{array}$ & 3 \\
\hline & & ARTEFATOS EM COURO & 5 \\
\hline
\end{tabular}

Gráfico 1: Total de empresas do Território do Sisal. Quadro 1:Tipos de produções e números das empresas rurais. Elaboração: Betânia Machado, 2017.

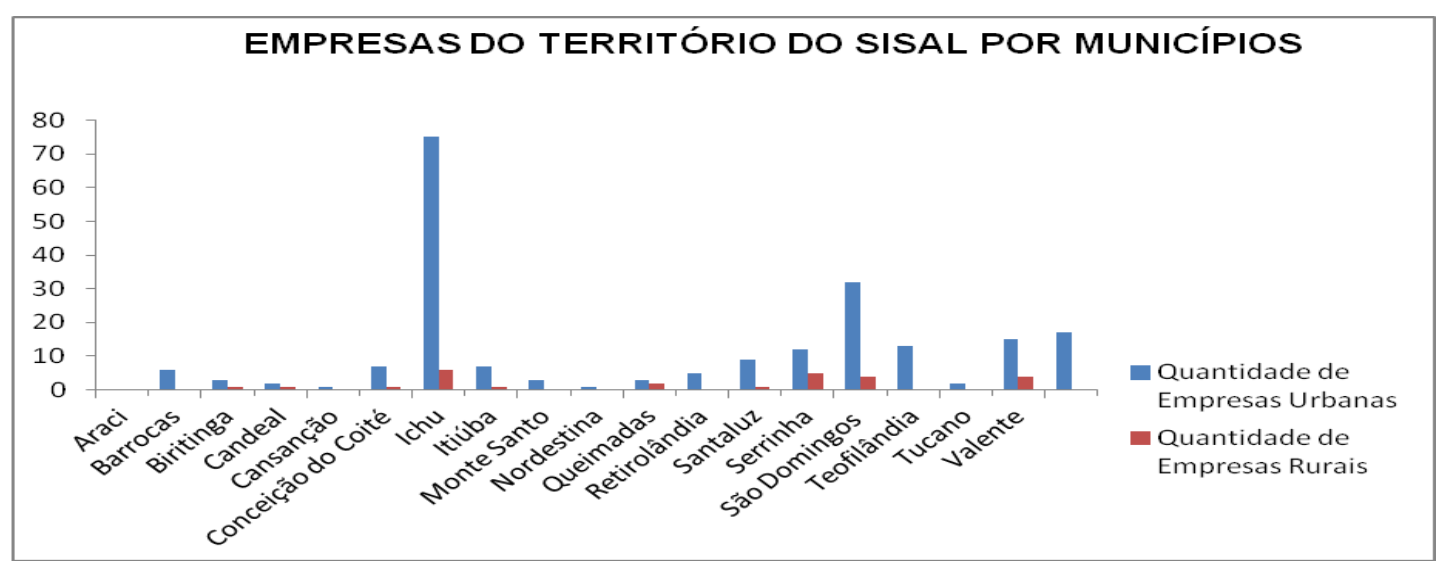

Gráfico 2: Empresas do Território do Sisal

.Elaboração: Betânia Machado, 2017.

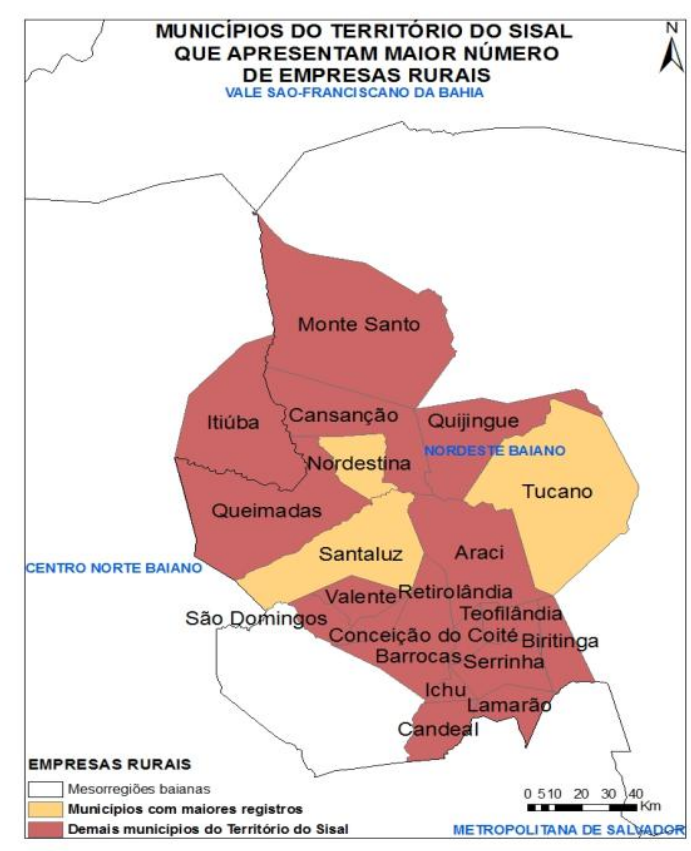

Figura 2: Municípios do Território do Sisal que apresentam maior número de empresas rurais. Elaboração: Betânia Machado, 2017. 


\section{CONSIDERAÇÕES FINAIS}

Ao pesquisar os dados de empresas registrados na FIEB dos municípios do Território do Sisal, a fim de medir o desenvolvimento de empresas rurais do território do sisal e as relações urbano-rural, percebe realmente um processo reverso na pequena cidade. Justamente esse processo se dar pelo fato que as empresas rurais registradas possuem importância na dinamização da economia, bem como a geração de empregos, tornando-se um atrativo para os moradores da zona urbana.

Considerando que as empresas urbanas em quantidade, são maiores que as rurais e que a principal atividade desenvolvida no rural está ligada principalmente na extração mineral e metais preciosos, compreende-se que os municípios do Território do Sisal, que historicamente, teve sua base de produção econômica a agave sisalana e a produção pecuária, vem ao longo doas anos desmistificando suas produções e indo para a extração geológica nas zonas rurais.

\section{REFERÊNCIAS}

ANCELES, Pedro Einstein dos Santos. Manual de tributos da atividade rural. São Paulo: Atlas, 2001.

MARCONI, M. A.; LAKATOS, E. M. (1996). Técnicas de pesquisa: planejamento e execução de pesquisas, amostragens e técnicas de pesquisa, elaboração, análise e $\begin{array}{llllll}\text { interpretação de } & \text { dados. } & \text { 6.ed. } & \text { São } & \text { Paulo: } & \text { Atlas. }\end{array}$

MARQUES, T. S. Dinâmicas territoriais e as relações urbano-rurais. Revista da Faculdade de Letras - Geografia I série, vol. XIX, Porto, 2003, pp. 507-521.

MOREIRA, R.J.; GAVIRIA, M.R. Territorialidades, ruralidades e assimetrias de poder na Comunidade de Taquari. Estudos Sociedade e Agricultura: Revista semestral

de ciências sociais aplicadas ao estudo do mundo rural. Rio de Janeiro, n. 18, p. 47-72, abril 2002. Disponível em: Acesso em: 11-06- 2008.

SECRETARIA DE PLANEJAMENTO DO ESTADO DA BAHIA - SEPLAN. Plano Plurianual 2004-2007: Bahia: desenvolvimento humano e competitividade. Salvador

SILVA, O. A. da. Rede urbana e dinâmica regional no estado da Bahia: um olhar sobre o

Território do Sisal. In: Dias, P. C.; Santos, J. (Orgs). Cidades médias e pequenas: contradições, mudanças e permanências nos espaços urbanos. Salvador: SEI, (Série estudos e pesquisas, 94) 238 p. 2012. 